\title{
Presence of 5-hydroxyguaiacyl units as native lignin constituents in plants as seen by $\mathrm{Py}-\mathrm{GC} / \mathrm{MS}$
}

\author{
José C. del Río ${ }^{\mathrm{a}, *}$, Ángel T. Martínez ${ }^{\mathrm{b}}$, Ana Gutiérrez ${ }^{\mathrm{a}}$ \\ a Instituto de Recursos Naturales y Agrobiología de Sevilla, CSIC, P.O. Box 1052, 41080 Seville, Spain \\ ${ }^{\mathrm{b}}$ Centro de Investigaciones Biológicas, CSIC, Ramiro de Maeztu 9, E-28040 Madrid, Spain \\ Received 6 June 2006; accepted 9 November 2006 \\ Available online 11 December 2006
}

\begin{abstract}
The presence of 5-hydroxyguaiacyl moieties in the lignin from several plants has been assessed by Py-GC/MS. Different woody (eucalypt) and nonwoody (flax, hemp, kenaf, jute, sisal and abaca) angiosperms were selected for this study. The pyrolysis of whole fibers released lignin-derived products with $p$-hydroxyphenyl, guaiacyl and syringyl structures. Indeed, a series of compounds having a 5-hydroxyguaiacyl nuclei, including 3methoxycatechol, 5-vinyl-3-methoxycatechol and 5-propenyl-3-methoxycatechol, were detected and identified in all samples, although in lower amounts than the normal guaiacyl or syringyl compounds. The analysis of the lignins isolated from the same plants also showed the same 3methoxycatechol derivatives found after whole fiber pyrolysis. These compounds are supposed to arise from the pyrolysis of 5-hydroxyguaiacyl moieties, which are supposed to be native constituents of lignin in plants forming benzodioxane substructures.
\end{abstract}

(C) 2006 Elsevier B.V. All rights reserved.

Keywords: Lignin; Pyrolysis; 5-Hydroxyguaiacyl; Syringyl; Guaiacyl; Angiosperms; Benzodioxane

\section{Introduction}

Lignin, the second most abundant natural polymer after cellulose, is present in all vascular plants. Lignin is a complex phenylpropanoid polymer that derives mainly from the oxidative condensation of three $p$-hydroxycinnamyl alcohol monomers differing in their degree of methoxylation, the socalled $p$-coumaryl, coniferyl and sinapyl alcohols. These monolignols produce, respectively, the $p$-hydroxyphenyl $(\mathrm{H})$, guaiacyl (G) and syringyl (S) phenylpropanoid units when incorporated into the lignin polymer.

The first structural lignin models were published nearly 40 years ago [1-3]. These structural models showed the phenylpropane units attached to one another by a series of characteristic linkages $\left(\beta-O-4, \beta-5^{\prime}, 5-5^{\prime}, \beta-\beta^{\prime}\right.$, etc.). Since then, the knowledge of the lignin structure has expanded with new units and linkages. This is the case of the discovery of the dibenzodioxocin units $\left(5-5^{\prime} / \beta-\mathrm{O}-4^{\prime} / \alpha-\mathrm{O}-4^{\prime}\right.$ linkages $)$ in the last few years in softwoods and then in hardwoods and nonwoody

\footnotetext{
* Corresponding author. Tel.: +34 95 4624711; fax: +34 954624002. E-mail address: delrio@irnase.csic.es (J.C. del Río).
}

plants [4-11]. These new structures and others have been revealed by modern analytical and instrumental methods, particularly multidimensional nuclear magnetic resonance (NMR) showing ${ }^{1} \mathrm{H}-{ }^{13} \mathrm{C}$ correlations. However, despite the high number of studies, there is still a lack of knowledge on the exact chemical structure of lignin.

It is now becoming increasingly clear that lignins are derived from several more precursors than just the three traditional monolignols. Various acylated monolignols have been described, such as acetates, $p$-coumarates and $p$-hydroxybenzoates, always attached at the $\gamma$-carbon of the lignin sidechain [12-17]. Another example of a non-conventional monomer is that occurring in COMT (caffeic acid- $O$ methyltransferase)-deficient plants and deriving from truncated monolignol biosynthesis [9-11]. COMT is one of the two enzymes required to methoxylate guaiacyl precursors to produce sinapyl alcohols and eventually produce syringyl units in angiosperm lignins. If COMT is down regulated, 5hydroxyconiferyl alcohol is produced instead of sinapyl alcohol, and it is subsequently incorporated into lignin analogously to other lignin monomers. The incorporation of 5-hydroxyconiferyl alcohol into lignins has been documented in previous works $[9-11,18-20]$. The incorporation of these 
units results in new substructures, benzodioxanes, in the lignin polymer [9-11].

The presence of 5-hydroxyguaiacyl nuclei has been reported in the lignin of stem cell walls of a brown midrib mutant $b m 3$ of maize (Zea may), together with normal $\mathrm{G}$ and $\mathrm{S}$ nuclei, by using thioacidolysis [18]. Interestingly, these authors also detected trace amounts of 5-hydroxyguaiacyl nuclei in the lignin of stem cell walls of the corresponding normal strain of maize [18]. Likewise, other authors confirmed, by using pyrolysis-gas chromatography/mass spectrometry (Py-GC/MS), the presence of 5-hydroxyguaiacyl nuclei in the lignin from brown hybrid mutants of maize [20]. It was also demonstrated that 5hydroxyguaiacyl nuclei are present, although in lower amounts, in the normal counterparts as well as in normal temperate and tropical plants [20]. Based on those results, it has been suggested that 5-hydroxyconiferyl alcohol is also involved in dehydrogenative polymerization during lignin biosynthesis in some plants.

Py-GC/MS has already been shown to be a convenient tool for the rapid and sensitive analysis of lignin [17,21-24]. In the present paper, the lignins of a series of plants have been analyzed by Py-GC/MS of the whole lignocellulosic material or the isolated lignin in order to assess the presence of 5hydroxyguaiacyl moieties.

\section{Material and methods}

\subsection{Samples}

The samples used for this study consisted of woody and nonwoody angiosperms. Among the woody angiosperms, the wood of eucalypt (Eucalyptus globulus) was selected. The nonwoody angiosperms consisted of bast fibers obtained from the stalk phloem layer, and leaf fibers. Among the bast fibers, hemp (Cannabis sativa), flax (Linum usitatissimum), kenaf (Hibiscus cannabinus) and jute (Corchorus capsularis) were selected, while sisal (Agave sisalana) and abaca (Musa textilis) were selected among the leaf fibers. Wood and nonwoody fibers were finely ground to sawdust using a knife mill (Janke and Kunkel, Analysenmühle) before analysis. Lignin content was estimated by the Klason method [25]. Milled-wood lignin (MWL) was extracted from eucalypt wood according to the Björkman method [26]. Alkalilignins were extracted from nonwoody plants using $0.2 \mathrm{M} \mathrm{NaOH}$ (at $120^{\circ} \mathrm{C}$ ), precipitated at acid $\mathrm{pH}$, and washed with acidulated water before analysis.

\subsection{Pyrolysis-gas chromatography/mass spectrometry}

The pyrolysis of the samples was performed in duplicate with a Curie-point pyrolyser (Horizon Instruments Ltd.) coupled to a Varian Saturn 2000 GC/MS, using a $30 \mathrm{~m} \times 0.25 \mathrm{~mm}$ i.d., $0.25 \mu \mathrm{m}$ DB-5 column. Approximately $100 \mu \mathrm{g}$ of finely divided sample was deposited on a ferromagnetic wire, then inserted into the glass liner and immediately placed in the pyrolyser. The pyrolysis was carried out at $610{ }^{\circ} \mathrm{C}$. The chromatograph was programmed from $40{ }^{\circ} \mathrm{C}$ (1 min) to $300{ }^{\circ} \mathrm{C}$ at a rate of $6{ }^{\circ} \mathrm{C} / \mathrm{min}$. The final temperature was held for $20 \mathrm{~min}$. The injector, equipped with a liquid carbon dioxide cryogenic unit was programmed from $-30{ }^{\circ} \mathrm{C}$ ( $1 \mathrm{~min}$ ) to $300{ }^{\circ} \mathrm{C}$ at $200{ }^{\circ} \mathrm{C} / \mathrm{min}$, while the $\mathrm{GC} / \mathrm{MS}$ interface was kept at $300{ }^{\circ} \mathrm{C}$. The compounds were identified by comparing the mass spectra obtained with those of the Wiley and NIST computer libraries and those reported in the literature $[21,22]$. Relative peak molar areas were calculated for the guaiacyl and syringyl lignin pyrolysis products and the data for two repetitive experiments were averaged. The relative standard deviation for the pyrolysis data was less than $10 \%$.

\subsection{DFRC (derivatization followed by reductive cleavage)}

Lignins $\left(10 \mathrm{mg}\right.$ ) were stirred for $2 \mathrm{~h}$ at $50{ }^{\circ} \mathrm{C}$ with acetyl bromide in acetic acid (8:92). The solvents and excess of bromide were removed by rotary evaporation. The products were then dissolved in dioxane/acetic acid/water (5:4:1, v/v/v), and $50 \mathrm{mg}$ powered $\mathrm{Zn}$ was added. After $40 \mathrm{~min}$ stirring at room temperature, the mixture was transferred into a separatory funnel with dichloromethane and saturated ammonium chloride. The $\mathrm{pH}$ of the aqueous phase was adjusted to less than 3 by adding $3 \% \mathrm{HCl}$, the mixture vigorously mixed and the organic layer separated. The water phase was extracted twice more with dichloromethane. The combined dichloromethane fractions were dried over anhydrous $\mathrm{NaSO}_{4}$ and the filtrate was evaporated in a rotary evaporator. The residue was subsequently acetylated for $1 \mathrm{~h}$ in $1.1 \mathrm{~mL}$ of dichloromethane containing $0.2 \mathrm{~mL}$ of acetic anhydride and $0.2 \mathrm{~mL}$ pyridine. The acetylated lignin degradation compounds were collected after rotary

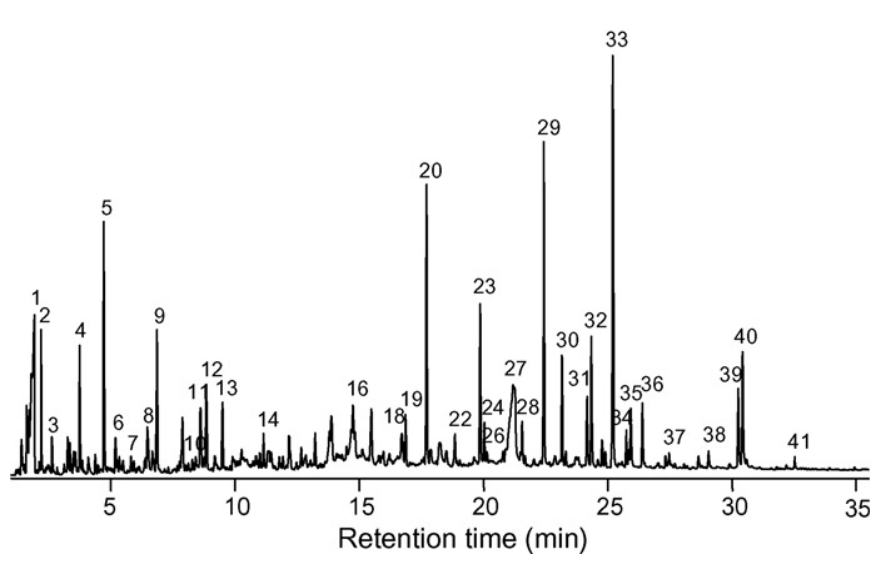

Fig. 1. Pyrogram of a selected sample (kenaf bast fiber). The identities of the peaks shown in Figs. 1, 3 and 4 are as follows-1: hydroxyacetaldehyde, 2: 3hydroxypropanal, 3: $(3 H)$-furan-2-one, 4: butane-2,3-dione, 5: 2-furaldehyde, 6: 2-(hydroxymethyl)furan, 7: 4-methyltetrahydrofuran-3-one, 8: $(5 H)$-furan-2one, 9: 2,3-dihydro-5-methylfuran-2-one, 10: phenol, 11: 5,6-dihydropyran2,5-dione, 12: 4-hydroxy-5,6-dihydro-(2H)-pyran-2-one, 13: 2-hydroxy-3methyl-2-cyclopenten-1-one, 14: guaiacol, 15: 4-vinylphenol, 16: 5-hydroxymethyl-2-furaldehyde, 17: 4-ethylguaiacol, 18: 1,4-dideoxy-D-glycerohex-1enepyrenone-3-ulose, 19: 4-vinylguaiacol, 20: syringol, 21: eugenol, 22: vanillin, 23: 4-methylsyringol, 24: trans-isoeugenol, 25: homovanillin, 26: acetoguaiacone, 27: levoglucosane, 28: 4-ethylsyringol, 29: 4-vinylsyringol, 30: 4allylsyringol, 31: cis-4-propenylsyringol, 32: syringaldehyde, 33: trans-4-propenylsyringol, 34: acetosyringone, 35: trans-coniferyl alcohol, 36: syringylacetone, 37: propiosyringone, 38: cis-sinapyl alcohol, 39: trans-sinapaldehyde, 40: trans-sinapyl alcohol, 41: trans-sinapyl acetate. 
evaporation of the solvents, and subsequently analyzed by GC/ MS.

The GC/MS analyses were performed with a Varian model Star 3400 GC equipped with an ion trap detector (Varian model Saturn 2000) using a medium-length (12 m) capillary column (DB-5HT, $5 \mathrm{~m} \times 0.25 \mathrm{~mm}$ i.d., $0.1 \mu \mathrm{m}$ film thickness) from $\mathrm{J} \& \mathrm{~W}$ Scientific. The oven was heated from $50(0.2 \mathrm{~min})$ to $100{ }^{\circ} \mathrm{C}$ at $30{ }^{\circ} \mathrm{C} / \mathrm{min}$, then raised up to $300{ }^{\circ} \mathrm{C}$ at $5{ }^{\circ} \mathrm{C} / \mathrm{min}$, and held for $5 \mathrm{~min}$ at the final temperature. The injector and transfer line were kept at $300{ }^{\circ} \mathrm{C}$. Helium was used as the carrier gas at a rate of $2 \mathrm{~mL} / \mathrm{min}$.

\section{Results and discussion}

The lignin of a series of nonwoody angiosperms, including monocotyledons (sisal and abaca) and dicotyledons (flax, hemp, kenaf and jute), as well as a woody angiosperm (eucalypt), were analyzed by Py-GC/MS. Fig. 1 shows the Py-GC/MS of a selected sample (kenaf bast fiber). The main released compounds derived from the carbohydrate and lignin polymers. Among the lignin (and $p$-hydroxycinnamic acid) products, compounds with $\mathrm{H}, \mathrm{G}$ and $\mathrm{S}$ structures were released from the different samples. The H, G and S-type compounds were identified, respectively, as phenol (peak 10), guaiacol (peak 14), syringol (peak 20), and their 4-methyl (peak 23), 4-ethyl (peaks 17 and 28), 4-vinyl (peaks 15, 19, 29), 4-allyl (peaks 21 and 30) and 4-propenyl (peaks 24, 31, 33) derivatives. Several oxidized phenols, such as vanillin (peak 22), homovanillin (peak 25), acetoguaiacone (peak 26), syringaldehyde (peak 32), acetosyringone (peak 34), syringylacetone (peak 36), propiosyringone (peak 37) and sinapaldehyde (peak 39) were also identified.

However, a close look at the pyrolysis products revealed that, in addition to the products with $\mathrm{H}, \mathrm{G}$ and $\mathrm{S}$ structures, another compounds having a 5-hydroxyguaiacyl (5-OHG) structure were detected. These compounds include 3-methoxycatechol (I), 5-vinyl-3-methoxycatechol (II) and 5-propenyl-3-methoxycatechol (III), and their structures and mass spectra are shown in Fig. 2. Although 3-methoxycatechol (I) has usually been found
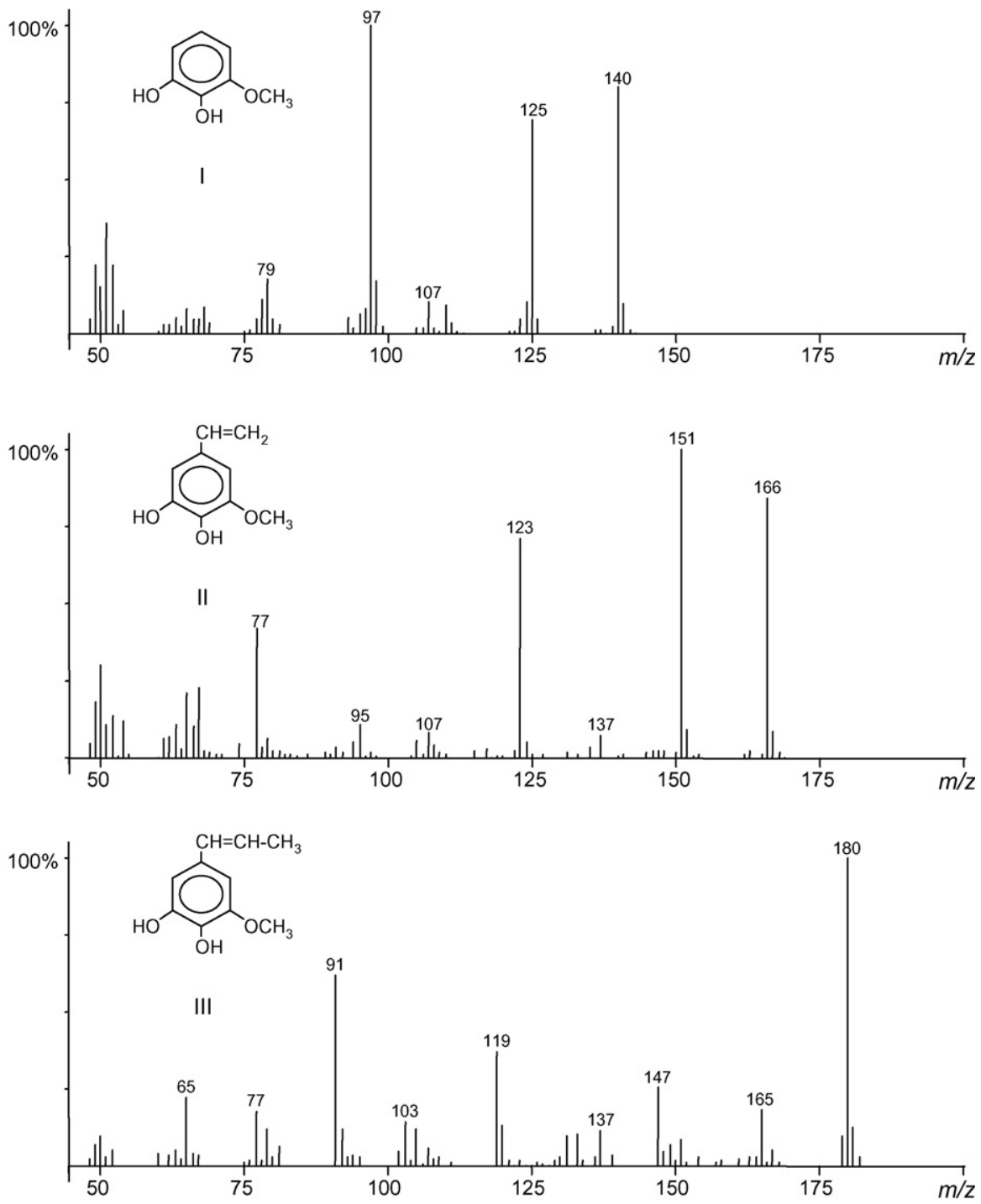

Fig. 2. Structures and mass spectra of the 5-hydroxyguaiacyl compounds released in the pyrolysis: 3-methoxycatechol (I), 5-vinyl-3-methoxycatechol (II) and 5propenyl-3-methoxycatechol (III). 
among lignin pyrolyzates [22,27,28], compounds II and II have rarely been detected. The presence of these compounds (I-III) was reported in relatively high amounts in the pyrolyzates of brown hybrid mutants $b m 3$ of maize, with low $O$-methyltransferase activity [20]. Indeed, these compounds were also found among the pyrolysis products of normal and temperate plants, including abaca (Musa textilis) [20], which was also selected for the present study. These compounds are supposed to arise from the pyrolysis of 5-hydroxyguaiacyl lignin moieties. The detection of 5-vinyl-3-methoxycatechol may also suggest the presence of 5-hydroxyferulic acid esterified and/or etherified to cell wall polymers [20]. However, this compound, or the methylated sinapic acid, did not seem to be present since they were not detected in the samples included in the present study after analysis by Py-GC/MS in the presence of TMAH.

Demethylation of the methoxyl groups of $\mathrm{S}$ nuclei were ruled out as the origin of these compounds because Py-GC/MS of different $\mathrm{S}$ lignin model compounds did not produce demethylation, in agreement with previous reported data [20]. Indeed, if demethylation was caused during pyrolysis, samples with higher S/G ratio should give much more abundance of 5hydroxyguaiacyl derivatives as pyrolysis products. However, it was demonstrated that transgenic plants of sorghum and maize, that have lower $\mathrm{S} / \mathrm{G}$ ratio than the normal strains, gave higher quantities of the 5-hydroxyguaiacyl products upon pyrolysis than those of normal counterparts, which strongly supported the presence of 5-hydroxyguaiacyl nuclei in native lignin of the transgenic plants and their normal counterparts [20].

The 5-hydroxyguaiacyl moieties (I-III) were detected in all of the plant samples selected for this study, although in small amounts. Fig. 3 shows the presence of 5-hydroxyguaiacyl moieties in the pyrolyzates of representative plant samples, a woody angiosperm (eucalypt), a nonwoody monocotyledon (abaca) and a nonwoody dicotyledon (kenaf). As noted above, the presence of these units in abaca lignin was already reported [20]. The relative amounts of 5-OHguaiacol $(=3$-methoxycatechol $)$ to guaiacol and syringol in the pyrolyzates of the plants were calculated from the peak areas of the respective compounds (Table 1). The 5-OHguaiacol/guaiacol ratio is higher in the samples with high $\mathrm{S} / \mathrm{G}$ lignin ratio, while the 5-OH-guaiacol/syringol ratio is higher in the samples with low $S / G$ ratio. Similar results have been found in other plants [20].

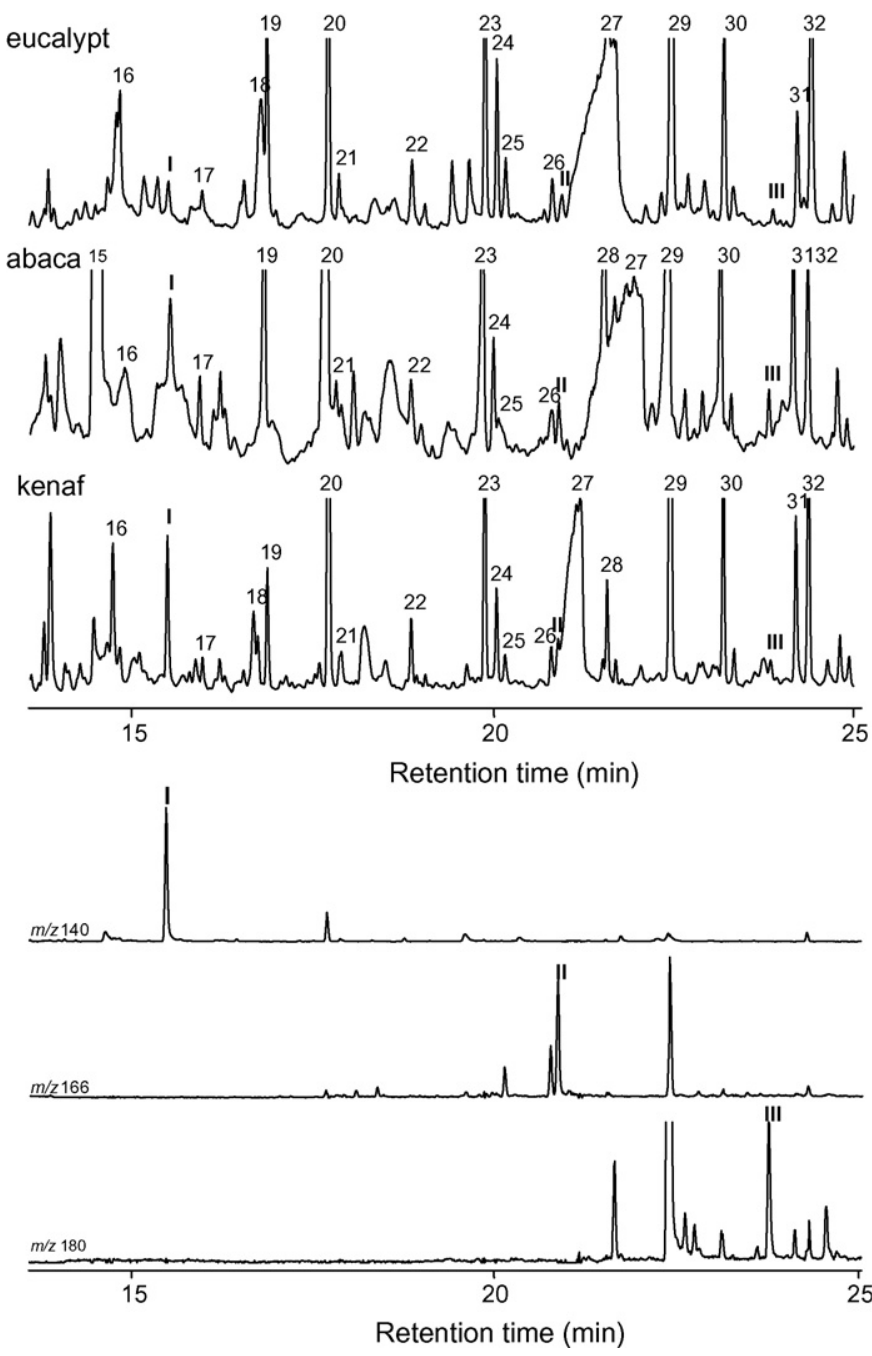

Fig. 3. Detection of the 5-hydroxyguaiacyl units in the pyrogram of selected plants. Top: detail of total ion pyrograms of a woody angiosperm (eucalypt wood), a nonwoody monodicotyledon (abaca leaf fiber) and a nonwoody dicotyledon (kenaf bast fiber). Bottom: reconstructed pyrograms showing 3methoxycatechol (I: $\mathrm{m} / \mathrm{z}$ 140), 5-vinyl-3-methoxycatechol (II: $\mathrm{m} / \mathrm{z}$ 166) and 5propenyl-3-methoxycatechol (III: $\mathrm{m} / \mathrm{z}, 180$ ) in a selected sample (kenaf). For peak identification refer to Fig. 1.

Table 1

Lignin content (as Klason lignin), and S/G ratio and relative abundance of 5-OH-guaiacol (=3-methoxycatechol) estimated by Py-GC/MS of the different plants selected for this study belonging to the monocotyledons or dicotyledons groups

\begin{tabular}{lcccc}
\hline & Klason lignin & S/G & 5-OH-guaiacol/guaiacol & 5-OH-guaiacol/syringol \\
\hline Nonwoody angiosperms & & & & 0.20 \\
$\quad$ Flax (Linum usitatissimum; Dicot) & 2.9 & 0.3 & 0.65 & 0.34 \\
Hemp (Cannabis sativa; Dicot) & 4.6 & 0.6 & 1.77 & 0.15 \\
$\quad$ Kenaf (Hibiscus cannabinus; Dicot) & 12.2 & 2.1 & 0.95 & 0.18 \\
Jute (Corchorus capsularis; Dicot) & 13.3 & 4.0 & 1.58 & 0.18 \\
$\quad$ Sisal (Agave sisalana; Monocot) & 10.8 & 4.5 & 1.90 & 0.15 \\
$\quad$ Abaca (Musa textilis; Monocot) & 11.8 & & & 0.07 \\
Woody angiosperm & 18.7 & 5.4 & 0.61 & \\
$\quad$ Eucalypt (Eucalyptus globulus; Dicot) & & & \\
\hline
\end{tabular}



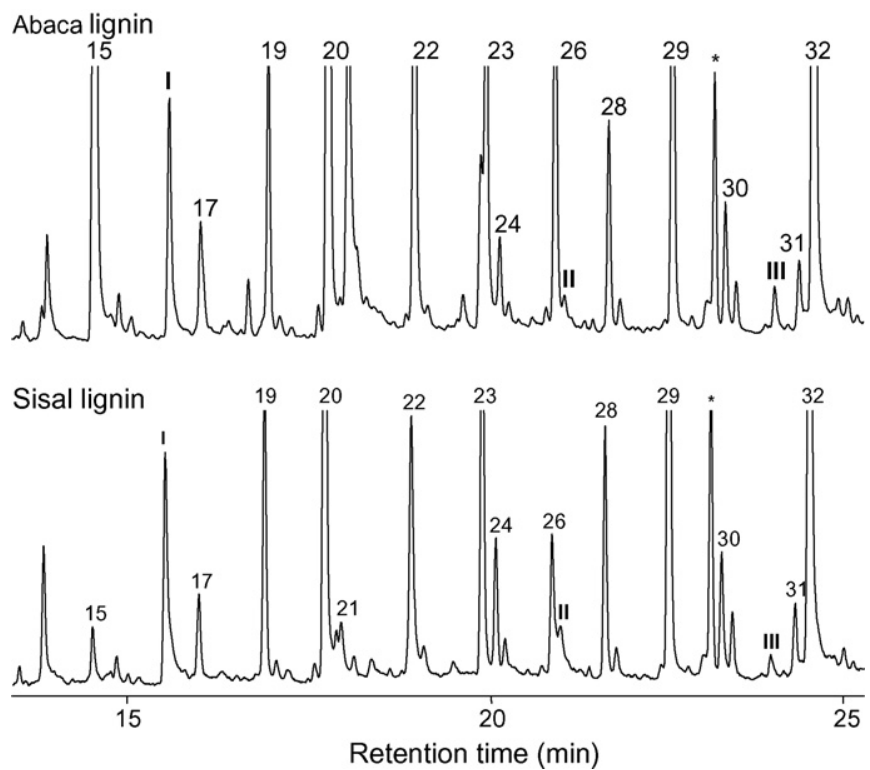

Fig. 4. Detection of the 5-hydroxyguaiacyl units in the pyrogram of isolated lignins from selected plants. I: 3-methoxycatechol; II: 5-vinyl-3-methoxycatechol; III: 5-propenyl-3-methoxycatechol. For the identification of the rest of the peaks refer to Fig. 1. *: Phthalate.

To exclude the possibility that these compounds might arise from different moieties other than lignin, the presence of 5hydroxyguaiacyl units was also assessed in the lignins isolated from the different fibers. Fig. 4 shows presence of 5hydroxyguaiacyl units in the pyrograms of selected isolated lignins, while the relative abundances of these moieties are shown in Table 2. These moieties were found in the isolated lignins in a similar abundance than in the respective fiber, confirming that they are part of the lignin structure. As in the case of whole fibres, 3-methoxycatechol showed lower abundances than syringol, but higher than guaiacol in high $\mathrm{S} / \mathrm{G}$ ratio lignins (such as those from sisal and abaca).

The present work seems to confirm the presence of 5hydroxyguaiacyl moieties in native lignin of normal plants, as already shown by other authors $[18,20,29]$. In COMT-deficient angiosperms, where 5-hydroxyconiferyl alcohol is synthesized instead of sinapyl alcohol, the former alcohol has been suggested to act as an authentic monolignol. In COMT-deficient angiosperms this monolignol is incorporated into the lignin
Table 2

Relative abundance of the 5-hydroxyguaiacol (=3-methoxycatechol and S/G ratio after Py-GC/MS of the lignins isolated from the different plants selected for this study

\begin{tabular}{llll}
\hline & S/G & 5-OH-guaiacol/guaiacol & 5-OH-guaiacol/syringol \\
\hline Alkalilignins & & & \\
$\quad$ Flax & 0.4 & 0.08 & 0.08 \\
Hemp & 0.8 & 0.28 & 0.19 \\
Jute & 1.7 & 0.80 & 0.25 \\
Sisal & 3.4 & 1.42 & 0.21 \\
Abaca & 2.9 & 1.34 & 0.12 \\
MWL & & & \\
$\quad$ Eucalypt & 4.8 & 0.48 & 0.10 \\
\hline
\end{tabular}

polymer forming a new type of cyclic benzodioxane structures $[9,10]$. In normal plants, 5-hydroxyguaiacyl moieties are also probably forming benzodioxane units. Traces of benzodioxane structures have been observed in normal plants by thioacidolysis [30] and NMR techniques [31]. Indeed, benzodioxane units were also observed in hydropyrolysis products of the lignin from Fraxinus mandshurica var. japonica by Hwang and Sakakibara [32] who were the first to suggest that 5hydroxyconiferyl alcohol could be incorporated into lignin.

In order to confirm the presence of benzodioxane structures in the lignins studied here, these were also analyzed by the socalled DFRC (derivatization followed by reductive cleavage) chemical degradation method, which leaves benzodioxanes intact and releases its acetylated derivatives [11,33-35]. Interestingly, a compound with a mass spectrum (Fig. 5) very similar to that previously published for the benzodioxane dimer marker released after DFRC [35] could be released from most of the lignins analyzed, although in trace amounts, indicating that 5-hydroxyguaiacyl moieties were incorporated into the lignins of normal plants forming benzodioxane structures.

While the presence of 5-hydroxyguaiacyl units in abaca (Musa textilis) and other temperate and tropical plants has already been reported [20], this paper broadens the range of plants in which these units are found. The fact that 5hydroxyguaiacyl units are present in monocotyledons and dicotyledons, woody and nonwoody angiosperms, points out that they might be widespread among the angiosperms.

Finally, it is interesting to note that some of the samples selected for this study (namely kenaf, jute, sisal and abaca),

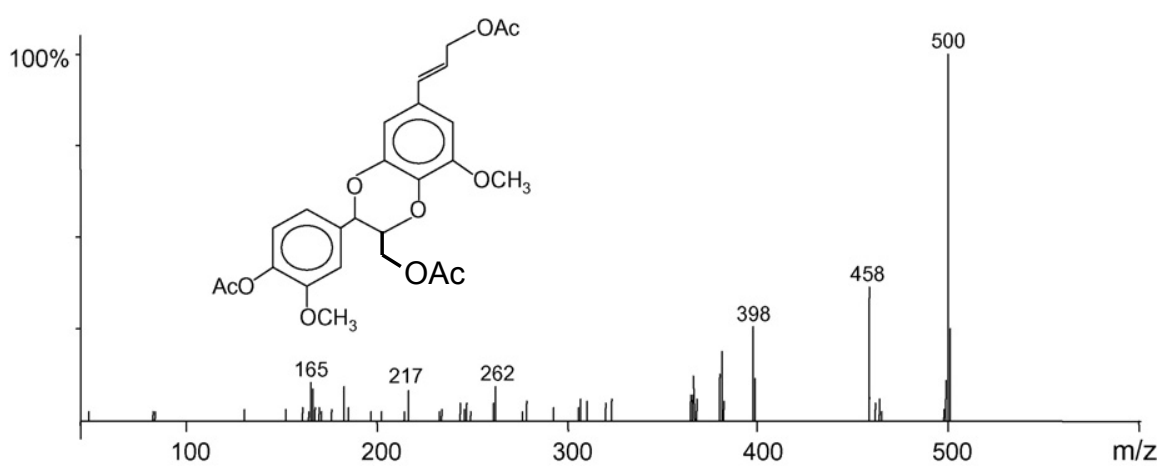

Fig. 5. Mass spectrum of the DFRC benzodioxane marker identified in the lignin samples. 
have already been shown to have coniferyl and sinapyl alcohol acetates (peak 41) [17,36] that seem to act as real lignin monomers during lignification [15]. However, while the acetylated monomers have only been found, until now, in nonwoody angiosperms with high $\mathrm{S} / \mathrm{G}$ ratio, the 5-hydroxyconiferyl lignin units seem to appear, although in low amounts, in many plants.

\section{Conclusions}

Py-GC/MS is a powerful and extremely sensitive analytical tool to detect the 5-hydroxyconiferyl units in lignocellulosic materials. It has been demonstrated that these units are present, although in low amounts, in the lignin of normal plants where they form benzodioxane substructures.

\section{Acknowledgements}

This study has been supported by the Spanish Ministerio de Ciencia y Tecnología (MCyT) and FEDER funds (project AGL2005-01748) and the EU project BIORENEW (NMP2CT-2006-026456). We thank CELESA S.A. (Tortosa, Spain) for providing the nonwoody plant samples, and ENCE for providing the eucalypt wood sample.

\section{References}

[1] K. Freudenberg, in: K. Freudenberg, A.C. Neish (Eds.), Constitution and Biosynthesis of Lignin, Springer-Verlag, New York, 1968, pp. 47-74.

[2] H.H. Nimz, Angew. Chem. Int. Ed. 13 (1974) 313-321.

[3] E. Adler, Wood Sci. Technol. 11 (1977) 169-218.

[4] P. Karhunen, P. Rummakko, S. Sipilä, G. Brunow, I. Kilpeläinen, Tetrahedron Lett. 36 (1995) 169-170.

[5] P. Karhunen, P. Rummakko, S. Sipilä, G. Brunow, I. Kilpeläinen, Tetrahedron Lett. 36 (1995) 4501-4504.

[6] S. Galkin, E. Ämmalähti, I. Kilpeläinen, G. Brunow, A. Hatakka, Holzsforschung 51 (1997) 130-134.

[7] E. Ämmälahti, G. Brunow, M. Bardet, D. Robert, I. Kilpeläinen, J. Agric. Food Chem. 46 (1998) 5113-5117.

[8] E.M. Kukkola, K. Haakana, S. Koutaniemi, H.T. Teeri, G. Brunow, P. Saranpää, I. Kilpeläinen, K. Ruel, K.V. Fagerstedt, in: Proceedings of the 8th International Conference Biotechnology in the Pulp and Paper Industry Pre-symposium on Recent Advances in Lignin Biodegradation and Biosynthesis, vol. 1, U. Helsinki Press, University of Helsinki, Finland, (2001), pp. 68-69.

[9] J. Ralph, C. Lapierre, J.M. Marita, H. Kinm, F. Lu, R.D. Hatfield, S. Ralph, C. Chapple, R. Franke, M.R. Hemm, J. van Doorsselaere, R.R. Sederoff,
D.M. O’Malley, J.T. Scott, J.J. MacKay, N. Yahiaoui, A.-M. Boudet, M. Pean, G. Pilate, L. Jouanin, W. Boerjan, Phytochemistry 57 (2001) 9931003.

[10] J. Ralph, C. Lapierre, F. Lu, J.M. Marita, G. Pilate, J. van Doorsselaere, W. Boerjan, L. Jouanin, J. Agric. Food Chem. 49 (2001) 86-91.

[11] J.M. Marita, J. Ralph, R.D. Hatfield, D. Guo, F. Chen, R.A. Dixon, Phytochemistry 62 (2003) 53-65.

[12] J. Ralph, R.D. Hatfield, S. Quideau, R.F. Helm, J.H. Grabber, H-.J.G. Jung, J. Am. Chem. Soc. 116 (1994) 9448-9456.

[13] R.C. Sun, J.M. Fang, J. Tomkinson, J. Wood Chem. Technol. 19 (1999) $335-356$.

[14] K. Kuroda, T. Ozawa, T. Ueno, J. Agric. Food Chem. 49 (2001) 18401847.

[15] F. Lu, J. Ralph, J. Chem. Soc., Chem. Commun. 1 (2002) 90-91.

[16] F. Lu, J. Ralph, Plant J. 35 (2003) 535-544.

[17] J.C. del Río, A. Gutiérrez, A.T. Martínez, Rapid Commun. Mass Spectrom. 18 (2004) 1181-1185.

[18] C. Lapierre, M.T. Tollier, B. Monties, CR Acad. Sci., Ser. 3 (307) (1988) $723-728$.

[19] G. Jacquet, PhD Thesis, Laboratoire de Chimie Biologique, Institut National de la Recherche Agronomique, Paris-Grignon, France, 1997.

[20] S. Suzuki, T.B.T. Lam, K. Iiyama, Phytochemistry 46 (1997) 695-700.

[21] O. Faix, D. Meier, I. Fortmann, Holz Roh-Werkstoff 48 (1990) 351354.

[22] J. Ralph, R.D. Hatfield, J. Agric. Food Chem. 39 (1991) 1426-1437.

[23] D. Meier, I. Fortmann, J. Odermatt, O. Faix, J. Anal. Appl. Pyrolysis 74 (2005) 129-137.

[24] T. Ohra-aho, M. Tenkanem, T. Tamminem, J. Anal. Appl. Pyrolysis 74 (2005) 123-128.

[25] Tappi, Test Methods 2004-2005, Tappi Press, Norcoss, GA, 2004.

[26] A. Björkman, Sven. Papperstidn. 13 (1956) 477-485.

[27] K. Kuroda, T. Ozawa, T. Ueno, J. Agric. Food Chem. 49 (2001) 18401847.

[28] K. Kuroda, A. Nakagawa-izumi, B.B. Mazumder, Y. Ohtani, K. Sameshima, Ind. Crops Prod. 22 (2005) 223-232.

[29] L. Li, Y. Zhow, X. Cheng, J. Sun, J.M. Morita, J. Ralph, V.L. Chiang, Proc. Natl. Acad. Sci. 100 (2003) 4939-4944.

[30] L. Joanin, T. Goujon, R. Sibout, B. Pollet, I. Mila, B. Maba, J. Ralph, M. Petit-Conil, C. Lapierre, in: Proceedings of the 11th International Symposium on Wood and Pulping Chemistry, Nice, France, (2001), pp. 25-28.

[31] J. Ralph, K. Lundquist, G. Brunow, F. Lu, H. Kim, P.F. Schatz, J.M. Marita, R.D. Hatfield, S.A. Ralph, H. Christensen, W. Boerjan, Phytochem. Rev. 3 (2004) 29-60.

[32] B.H. Hwang, A. Sakakibara, Holzforschung 35 (1981) 297-300.

[33] F. Lu, J. Ralph, J. Agric. Food Chem. 45 (1997) 2590-2592.

[34] F. Lu, J. Ralph, J. Agric. Food Chem. 45 (1997) 4655-4660.

[35] C. Lapierre, H. Kim, F. Lu, J.M. Marita, I. Mila, B. Pollet, J. Ralph, Proceedings of the 11th International Symposium on Wood and Pulping Chemistry, Nice, France. Association Technique de l'Industrie Papetière (ATIP), Paris, (2001) pp. 23-26.

[36] A. Gutiérrez, I.M. Rodríguez, J.C. del Río, J. Agric. Food Chem. 52 (2004) 4764-4773. 